\title{
Pragmatic Empathy as a Grand Strategy in Business Letter Writing
}

\author{
Xu Zhanghong ${ }^{1} \&$ Wang Qian ${ }^{1}$ \\ ${ }^{1}$ School of English for International Business, Guangdong University of Foreign Studies, Guangzhou, China \\ Correspondence: Xu Zhanghong, School of English for International Business, Guangdong University of \\ Foreign Studies, Guangzhou, China. E-mail: 1458975262@qq.com
}

Received: June 10, 2018 Accepted: July 7, 2018 Online Published: July 9, 2018

doi: 10.5539/elt.v11n8p14 URL: http://doi.org/10.5539/elt.v11n8p14

\begin{abstract}
This paper examines the employment of pragmatic empathy as a grand strategy in business letter writing. To account for the realization of pragmatic empathy in business letters, we make a corpus-based manual analysis of four types of business letters. It is found that (1) the choice of deixis is a major concern in most letters: while second person is often used in competitive letters, first or third person frequently appears in other three types of letters; (2) conventionalized indirectness strategy is often used in competitive business letters while mitigation strategy is preferred in conflictive business letters; (3) the employment of different strategies is an adaptation to various empathetic concerns in business letter writing. It is concluded that different types of business letters are characterized by different pragmatic strategies to achieve empathy. This paper, which is an attempt to investigate business letters from the empathy perspective, sheds light on business discourse research in general and business letter writing in particular.
\end{abstract}

Keywords: pragmatic empathy, business letter writing, pragmatic strategies, empathetic concern

\section{Introduction}

As a major communication tool in international business interactions, business letter writing is "a written-language-based social practice of business interaction realized through letter exchanges for the purpose of business promotion" (Zhou, 2007). It differs stylistically from the daily letters as shown at lexical, syntactic and textual levels (Liu \& Wang, 2016).

Experience-based guiding principles for business letter writing evolve in decades, among which the "7Cs" principle and You-attitude principle are widely recognized. The " $7 \mathrm{Cs}$ " principle consists of 7 basic requirements for business letter writing, initiated with the letter "C", i.e., correctness, conciseness, clarity, concreteness, completeness, courtesy, and consideration. The former " $5 \mathrm{Cs}$ " concentrates on communication efficiency whereas the latter " $2 \mathrm{Cs}$ " cater for interactional harmony.

You-attitude principle has also drawn much attention among scholars, who, however, perceive it in slightly different ways. Sorrels (1984) regards You-attitude as "genuine empathy-focus on the reader's needs and point of view" which will "pervade the entire message". Wilkinson, Wilkinson and Vik (1986) take You-attitude as a state of mind with which people bring out and emphasize the benefits to others and subordinate or eliminate their own. Both definitions imply that in business communication You-attitude refers to consideration that one party renders to the other. In this sense, "7Cs" and You-attitude share some similarities.

An effective business letter, according to Wang (1995), often presents the tone of You-attitude, which shows concern for the situation and position of the other side. The manifestation of You-attitude in business letters not only lies in the frequent adoption of the first person pronouns "I" and "we", but also is a matter of spiritual attitude - the letter-writing part shall express sincere consideration for the recipient part. You-attitude is a process of genuine empathy, with which the writer focuses on the reader's needs and points of view. Scholars highlight the effect of empathy, insisting that You-attitude cannot be only presented on the surface, that is, to adopt the second person only, but rather it should be a guiding principle which integrates both courteous writing forms and a sincere mood in order to establish harmonious relationship with the other part.

Theory-based guiding principles for business letter writing are also attempted by linguistic researchers, who derive their theoretical support from such theories as the cooperative principle (CP), the politeness principle (PP) and the relevance theory (RT). Zhou (2007) thinks that there is high consistency among CP, PP and business letter writing principles. Yet Zhou's research mainly discusses the violation of the cooperative principle in 
business letter writing without delving into the employment of PP in business letters. Li, Liu, and Guo (2001) study the pedagogical significance of PP and RT in business letter writing, stating that the two theories are used to achieve the interactional and the transactional function of language. Liu and Zheng (2015) studies business letter writing based on the face theory, proposing politeness strategies, either positive or negative, in order to establish and maintain sound business relations. Si (2003) also emphasizes the role of PP in business letter writing. On one hand, he argues for an intercultural concern for politeness in business letter writing since politeness differs among cultures. On the other, he provides several writing strategies to achieve politeness. Feng and Du-Babcock (2016) study the way Chinese university students construct cultural identities in business letter writing through discursive and meta-discursive acts, and find that the latter frequently employ politeness strategies to maintain face and harmony.

A review of literature on business letter writing shows that while the two experience-based guiding principles are widely accepted, PP is much preferred by researchers. However, PP cannot adequately explain why and how business letter writing is managed, as it involves not only the face wants of the recipients but also the substantial benefits and costs of the recipients. Given these factors, the present research attempts to investigate business letter writing from the perspective of pragmatic empathy, exploring how various pragmatic strategies are employed to achieve empathy, and ultimately realize the goal of business communication.

The article is structured as follows. In section 2 we will review some key notions and construct an analytic framework. Section 3 will then describe data collection and methodology, and will be followed in section 4 by a detailed analysis of the data. Section 5, the final section, will present conclusions, pointing out the limitations of the present study and making suggestions for further research.

\section{Key Notions and Analytic Framework}

This section will briefly review such key notions in this article as empathy, pragmatic empathy, and classification of business letter, followed by a proposed analytic framework.

\subsection{Empathy}

Empathy is originally an aesthetic concept as a translation for the German word einfühlung, which means "feeling into". Aesthetics describes empathy as the process of feeling into the emotions expressed in the movements or dynamic posture of people, aesthetic objects of natural scenes (Li, 2015). Similarly, psychologists regard empathy as the adoption of another's perspective without losing one's identity as observer (Hoffman, 2000). According to Bachelor (1988), empathy is described as either an affective phenomenon ('affective empathy'), relating to the emotions of another person, or as a cognitive phenomenon ('cognitive empathy'), referring to the intellectual understanding of another's experiences. Davis (1996) proposed a multi-factor model of empathy, involving empathetic concern, perspective-taking, identification with fictional characters and empathetic distress. More to the point of this article, we'll deal with both affective empathy and cognitive empathy, with a special focus on two factors of Davis's empathy model: empathetic concern and perspective-taking. Empathetic concern in this study refers to the letter-writer's overall consideration of the letter-receiver's face wants, and understanding of business situations and current and potential business relationships between them, and perspective-taking means that the devices the letter-writer employs to coordinate the relationship or to resolve their conflicts.

\subsection{Pragmatic Empathy}

Brown (1987) notes that a sophisticated degree of empathy is required in communication, suggesting that we need to be able to understand the other person's affective and cognitive states so as to obtain our communicative goals. Levinson (2001) also observes that the shift of deixis is designed to achieve empathy. Pragmatic empathy, according to He (1991), refers to the two communicating parties feeling into and understanding each other, which requires a speaker to think in the hearer's position or take full account of the hearer's needs in interpersonal communication. Through pragmatic empathy, a sense of emotional convergence is achieved between the two parties to shorten the psychological distance and build a harmonious relationship to obtain the desired communicative effect (Ran, 2007). In short, pragmatic empathy, a way to understand others by considering problems from the perspective of the other party, bridges the psychological gap between interlocutors and builds a pleasant business relationship, and ultimately acquires the desired communicative effect.

Granted that a major aim of business letter contact is to establish and maintain business relations, the pragmatic empathy is surely to be manifested in the letters. Pragmatic empathy consists of two parts: pragmatic-linguistic empathy and social-pragmatic empathy $(\mathrm{He}, 1991)$. The first concerns how speakers deliberately express their 
thoughts and intentions to hearers and how hearers catch the meanings correctly, and the second is about the social background of the two parties, either cultural or interpersonal. This paper mainly focuses on pragmatic-linguistic empathy to see in what ways empathy is achieved in business letter writing since "it can be realized through language using" (Ran, 2007).

As the principal aim of doing business is to maximize profits ( $\mathrm{Li}$ et al., 2001), two parties exchanging letters in business context are required to communicate with a concern of the benefit and the cost. To achieve pragmatic empathy, a letter sender should pay much attention to "your" benefit and cost, that is, the benefit and cost of the other side. It is worth noting that the phrase "benefit and cost" should be understood in two senses or dimensions: One is psychological dimension, mostly involving face wants in politeness theory (Brown \& Levinson, 1987), and the other material dimension, mainly referring to gain or loss in terms of money or profits. Therefore, pragmatic empathy can serve as a grand strategy to cater for the other person's cost and benefit at both intangible level and tangible or material level in business letter communication.

Scholars provide various pragmatic strategies to achieve empathy. Firstly, deixis can perform empathetic functions (e.g., Argaman, 2007; Gast, Deringer, Haas, \& Rudolf, 2015; He, 1991; Ran, 2007). Deixis, including person deixis, time deixis, place deixis, etc., is a grammatical feature tied directly to the circumstances of utterance, and belongs within the domain of pragmatics (Levinson, 1983). Deixis can be used in an empathetic sense: to indicate emotional or other psychological distance or proximity between speaker and referent (Argaman, 2007). Secondly, according to Li (2012), mitigation is another way of expressing empathy because it shares such traits of pragmatic empathy as perspective taking, emotional convergence and altruism. Li (2008) classifies mitigation into 3 three types according to Austin's speech act theory: propositional mitigation, illocutionary mitigation and perlocutionary mitigation. This article adopts Li's point of view and follows the sub-strategies proposed by him.

According to $\mathrm{Li}$ (2008), illocutionary mitigation "operates on the illocutionary non-endorsement, the non-insistence or non-determination with which the speaker gets on record performing the ensuing speech act," while perlocutionary mitigation "operates on the speaker's concern, directly or indirectly, over the possible negative effect that the current speech act is likely to produce on the hearer." The sub-strategies for illocutionary mitigation include disclaimers, deprecators, truth claimers, hesitators (Li, 2008) and request markers (Mao \& Pei, 2013). The sub-strategies for perlocutionary mitigation include simple anticipation, concern showing, penalty taking, direct dissuasion ( $\mathrm{Li}, 2008)$. Thirdly, Mood system, referred to as conventionalized indirectness (Brown \& Levinson, 1987: 131), can also be employed to achieve empathy (Ma \& He, 2011). To be specific, speech acts are often conventionally phrased with modals such as "can/could", "would like/want/I'd rather", and "would you be willing" (Searle, 1975) so as to be polite as well as easy to interpret (Reiter, Rainey, \& Fulcher, 2005).

This article integrates these pragmatic empathy models and examines their adaptability to business letters. Figure 1 shows the pragmatic empathy model we construct:

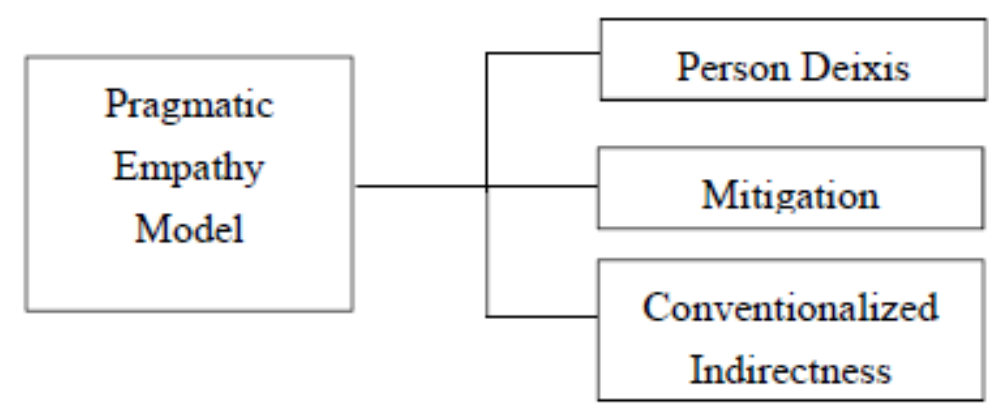

Figure 1. Pragmatic empathy model for business letter writing

\subsection{Classification of Business Letters}

Business communication is a process through which the parties involved establish relationships, negotiate terms and undertake transactions. Despite well-developed science and technology that brings great convenience to people, business letters are still the main channel and medium for business communication. As Cao (2003) puts it, a business letter is a written message aimed at persuading its recipient to take certain action or to adopt the intended attitude of the sender. The indispensable role of business letters in business communication lies in the 
fact that they can sometimes serve as written contract between the two parties of the business communication and thus acquire legal validity, which cannot be replaced by oral communication.

Business letters can be classified according to different standards. Firstly, business letters can be generally divided into three categories in terms of their purposes (Dong, Hao \& Zheng, 2013). They are to get action, to establish goodwill, and to furnish information respectively. Whatever the category or the writing purpose is, it should be kept in mind that the letter must be easy to read and understand as well as friendly and courteous if it is intended to achieve the desired communication effect.

Secondly, the categories of business letters can be divided in accordance with the procedure of international business transaction. Generally speaking, the whole procedure undergoes four stages, including preparing for exporting or importing, business negotiation, implementation of the contract, and settlement of disputes. In the first stage, relationship-establishing or promotion letters should be written out of the consideration that the two parties have not met and dealt with each other yet. In the second, letters such as inquiry, quotation, offer and counter-offer, order, and acceptance and rejection letters may be exchanged. When it comes to the third stage of contract implementation, there may include letters for $\mathrm{L} / \mathrm{C}$ amendment or for bills exchanging. In the last stage, complaint, claim and settlement letters may be put into use if there arouse disputes. Judging from their function, a list of letters can be made, including inquiry letters, offer letters, confirmation letters, notification letters, approval letters, collection letters, sales letters, refusal letters, claims and adjustments letters and some other special ones (Huang, 2002).

Thirdly, business letters can be categorized based on the illocutionary function, as observed by Huang (2002), for this criterion of classification helps to determine the interests of the two parties. Leech (1983) sets illocutionary functions into four categories: the competitive, the convivial, the collaborative, and the conflictive, according to how they "relate to the social goal of establishing and maintaining comity." For the competitive, the illocutionary goal competes with the social goal such as "asking" and "demanding". For the convivial, the illocutionary goal coincides with the social goal such as "thanking" and "congratulating". For the collaborative, the illocutionary goal is indifferent to the social goal such as "reporting" and "announcing". For the conflictive, the illocutionary goal conflicts with the social goal such as "accusing" and "threatening". Accordingly, business letters can be divided into competitive ones (e.g. application letters, collection letters, promotion letters, etc.), convivial ones (e.g. promise letters, thanks letters, invitation letters, etc.), collaborative ones (inquiry letters, offer letters, confirmation letters, notification letters, introduction letters, instruction letters, etc.), and conflictive ones (refusal letters, complaint letters, claim letters, etc.).

This article adopts Huang's classification of business letters and makes justifications for it from the perspective of pragmatic empathy.

\section{Data Collection and Methodology}

The data used in this research are collected from three sources of material: Cai (2003), T. C. Cheng and X. Cheng (2011), and Dong (2010). To be specific, the competitive, collaborative and conflictive business letters are from T. C. Cheng and X. Cheng (2011), Dong (2010) and the convivial business letters are from Cai (2003) because the former two books only deal with business trade letters while the latter contains business communication letters in which there are thanks letters, invitation letters and other convivial letters. Two sources of material are investigated to collect competitive, collaborative and conflictive business letters to avoid the impact of the personal style of each single author(s).

The competitive business letters, which refer to those of which the illocutionary goal competes with the social goal, include application letters, collection letters, sales promotion letters, etc. All samples in the sales promotion chapter and the payment chapter in T. C. Cheng and X. Cheng (2011) and those in the payment chapter in Dong (2010) are analyzed to determine (1) whether they are qualified letters of the competitive sort and (2) how the competitive speech act is performed. Apart from 2 payment letters in T. C. Cheng and X. Cheng (2011) that belong to the collaborative category and 4 payment letters in Dong (2010) that either belong to the conflictive category or serve as reply letters, a total of 19 pieces of competitive letters are analyzed, including 7 sales promotion letters and 4 payment letters in T. C. Cheng and X. Cheng (2011) plus 8 payment letters in Dong (2010).

Competitive business letters, which highlight the speech act of which the illocutionary goal competes with the social goal, contain more speech acts than those expressing competitive illocutionary goals. For example, sales promotion letters are written to ask or persuade the potential buyers to purchase products, which generally consist of an introduction of the product, an intention for business, and a further persuasion if necessary. Some of the payment letters are written to stipulate payment terms and conditions, and some are written to urge the other 
for action, in which a competitive speech act is realized. In this regard, the inspecting efforts are mainly made to pick out the competitive speech act as the research target at this stage.

The convivial business letters, which refer to those of which the illocutionary goal coincides with the social goal, include promise letters, invitation letters, thanks letters and some other letters. A total of 19 convivial letters are collected in Cai (2003) for analysis, among which there are 4 letters of invitation, 4 of welcome, 6 of congratulations and 5 of thanks.

The collaborative business letters, whose illocutionary goal is indifferent to the social goal, include enquiry letters, offer letters, confirmation letters, notification letters and some other letters. Letters of the shipment chapter in Dong (2010) and those of the packing chapter in T. C. Cheng and X. Cheng (2011) are analyzed. A total of 13 valid letters are collected.

The conflictive business letters, whose illocutionary goal conflicts with the social goal, mainly include refusal letters and complaint and claim letters. To account for the demonstration of empathy in conflictive business letters, letters of the complaints and claims chapter in Dong (2010) and those of the claim and settlement chapter in T. C. Cheng and X. Cheng (2011) are analyzed. Apart from 6 letters of positive reply, there are 14 pieces of conflictive letters valid in total, 11 from Dong (2010) and 3 from T. C. Cheng and X. Cheng (2011). For each piece of letter, major attention is paid to expressions and sentences that convey refusal, complaints or claims. As a result, such specific expressions and sentences are picked out for analysis rather than the whole letters.

\section{Data Analysis}

This section discusses in detail in what ways pragmatic empathy serves as a grand strategy in guiding business letter writing and how it is manifested through sub-strategies. Four kinds of business letters are classified as competitive letters, convivial letters, competitive letters and conflictive letters as proposed by Huang (2002).

\subsection{Pragmatic Empathy in Competitive Business Letters}

The competitive speech acts in a total of 19 pieces of letters are picked out for analysis. Table 1 shows their patterns of empathy realization.

Table 1. Pragmatic empathy in the competitive business letters

\begin{tabular}{llll}
\hline Letter No & Person Deixis & Mitigation & CI \\
\hline 1 & we enclose... for you & --- & we'd like to offer you... \\
2 & we hope to ... serve you & --- & we would suggest that... \\
3 & - -- & --- & -- - \\
4 & we... establish business relations with you & --- & we would recommend... \\
5 & (we) appreciate... & --- & we would like to export... \\
6 & --- & please find... & we shall appreciate your... \\
7 & we enclose ...(for you) & please put the samples... & --- \\
8 & we have not received.. & please do your utmost... & --- \\
9 & --- & --- & we shall be glad if ... \\
10 & --- & we regret to have to & --- \\
11 & --- & --- & --- \\
12 & --- & --- & would you please... \\
13 & let us have your... & please kindly... & --- \\
14 & --- & --- & would you please... \\
15 & --- & --- & --- \\
16 & --- & --- & would you please... \\
17 & --- & --- & we would be most grateful if... \\
18 & --- & --- & if you would... please... \\
& & we would appreciate it if.. \\
\hline
\end{tabular}




\begin{tabular}{llll}
\hline 19 & your kindness... will be... & --- & if you could ... \\
Total & 8 & 5 & 13 \\
\hline
\end{tabular}

Note. $\mathrm{CI}=$ Conventionalized Indirectness.

Here we focus on the business intention expression part of sales promotion letters and payment-urging letters, in which a competitive speech act is realized. Judging from all the competitive business letters collected we can find that the shift of person deixis and conventionalized indirectness are frequently used as strategies ( 8 letters in 19 adopt person deixis shifting and 13 employ conventionalized indirectness strategies), mitigation is occasionally used (5 in 19).

The above pattern of empathy realization can be explained as follows. First, competitive speech acts are to direct other people to do something as instructed, which in essence competes with the social goal of establishing and maintaining comity because the message-receiver receives instructions passively, in the form that the receiver pays the cost to benefit the message-sender. To achieve pragmatic empathy, letter-writers should think in the position of the letter-receivers that their request or demand might incur costs to the receivers but bring benefits to themselves, so they should provide a formal compensation when drafting relevant sentences. That is, they should start sentences with the first person plural "we" instead of the second person "you" to weaken the reality that the letter-receiver should actually be bothered to do something. For example:

(1) We'd like to offer you our "Moodmaker" lines which reach a standard sufficiently high to rebound to your credit (T. C. Cheng \& X. Cheng, 2011).

(2) We sincerely hope to have the opportunity to serve you (T. C. Cheng \& X. Cheng, 2011).

(3) We would like to export to your country, and appreciate any information regarding government regulations concerning the importation of the products to your country (T. C. Cheng \& X. Cheng, 2011).

(4) Since this is the first business contact between us, please kindly let us have your brief description on your payment terms used in the foreign trade practice (Dong, 2010).

Extract (1) is from a sales promotion letter in which the writer expresses their willingness to establish business relationship with the reader, hoping that the reader is interested in their products. The writer provides the reader with their product information, implying that the reader should take time to learn about it. By means of providing the relevant information, the writer is actually making a request. Instead of saying "please take a look at our product list", the writer implicitly converys their intention by saying "we offer you a product list for reference". A shift of deixis shows the writer's pragmatic empathy that they look at the issue from the perspective of the recipient. Such practice displays the writer's sincerity and makes the request much easier for the reader to accept.

Similarly, extract (2), drawn from a sales promotion letter, is to express the writer's intention to establish business relations with the reader. In this case, two parties are equal in status. However, by saying "we sincerely hope to have the opportunity to serve you" instead of "we want to establish business relations with you", the writer artfully turns the reader to a beneficiary through a shift of deixis.

Extract (3) makes a request more implicitly. This extract, drawn from a sales promotion letter written by the exporter to his potential importer, is to express his willingness to cooperate, hoping the importer to inform his of the information about the relevant government regulations in the importer's country. Instead of making the request directly, the writer express his intention by extending advanced appreciation. Again, literally it is the writer that is performing the speech act of thanking whereas in essence it is the reader that has to actually perform the act of providing information.

Extract (4) is written by an importer to an exporter asking about the payment terms. Deixis shifting is employed here again. "Please kindly let us have your..." takes the place of "please (you) send to us..." to serve as the pragmatic stance marker. In this way, the writer puts the reader in a higher status, making their request polite and sincere.

Second, conventionalized indirectness strategies are also frequently employed to make requests in competitive business letters, including general questions led by modal verbs such as could or would and conditional clauses led by if. Requesting in this way offers the readers some kind of freedom to determine whether or not to accept the requests or suggestions proposed by the writer. For example,

(5) We would greatly appreciate it if you could furnish us with the necessary information about the financial standing of the above firm (Dong, 2010). 
(6) As both these contracts are less then GBP 1,000 in value, we would appreciate it very much if you could ship the goods to us on T/T basis (Dong, 2010).

(7) Should you be unable to supply the goods exactly as specified, would you please offer goods of the nearest specifications or pass this enquiry to your associate who is able to make the right offer? (Dong, 2010).

(8) Would you please send us a price-list, stating the payment terms you usually accept for your exportation? We will place orders with you for the above-mentioned items if your offer is acceptable (Dong, 2010).

Extract (5) is drawn from a credit status enquiry, a letter written by one party to the bank of the other party with which they are gonging to establish business relations to ask about the credit status of the latter party, and extract (6) is drawn from a request letter for certain terms of payment. In the two examples, the structure of "we would appreciate it if you could..." is used to make requests. The structure is characterized by conditional clause and subjunctive mood, and when the two devices are used, the writer intentionally separates the real world from the virtual world, telling the reader the request is not a must in the real world but a suggestion and that the reader has the right to decide whether or not to accept it. In this way, the writer shows their empathy for the reader, which makes it easier for the writer's request to be accepted.

Extract (7), collected from a buyer who wants to buy goods from a seller, asks the seller to provide the latest specifications or pass the enquiry to others if they are not in a position to make the offer, and extract (8) is from a payment letter by a buyer, asking for a price-list from the seller. In the two examples, the structure of "would you please" is used. In business English, tone system is used for more than information acquisition (Zhang \& Miao, 2004), and the interrogative tone is often used by message-sender to encourage the active participation of the message-receiver in their communication (Ma \& He, 2011). In the two examples, the writer makes their requests by asking questions, which will free the reader from feeling being imposed on and let the reader enjoy the freedom to make decisions.

\subsection{Pragmatic Empathy in Convivial Business Letters}

The main purpose of the convivial business letters is to send good-news messages to the reader so as to establish and enhance sound business relations. Thus, these letters are characterized by positive words and expressions, which show the writer's sincere attitude. Empathy in this kind of letter is manifested when the reader's positive face is as much catered for as possible. Table 2 shows the use of each pragmatic empathy strategy in the convivial business letters.

Table 2. Pragmatic empathy in the convivial business letters

\begin{tabular}{|c|c|c|c|}
\hline Letter No & Person Deixis & Mitigation & $\mathrm{CI}$ \\
\hline 1 & $\begin{array}{l}\text { NADA...pay all your...; } \\
\text { we can offer you... }\end{array}$ & $\begin{array}{l}\text { Let me know } \\
\text { as soon as you can, please }\end{array}$ & would you serve as... \\
\hline 2 & $\begin{array}{l}\text {...since we had the opportunity } \\
\text { to service your automobile; } \\
\text { we have set aside... } \\
\text { for your convenience }\end{array}$ & --- & --- \\
\hline 3 & $\begin{array}{l}\text { we would be prepared to } \\
\text { offer you... }\end{array}$ & please let us know... & $\begin{array}{l}\text { we would be delighted } \\
\text { if you... }\end{array}$ \\
\hline 4 & --- & --- & (we) would like to invite you... \\
\hline 5 & $\begin{array}{l}\text { we are pleased to receive your letter...; } \\
\text { we shall be very happy to welcome you... }\end{array}$ & please let me know... & --- \\
\hline 6 & we are pleased that... & --- & --- \\
\hline 7 & ...how happy we are to learn that you... & --- & --- \\
\hline
\end{tabular}




\begin{tabular}{|c|c|c|c|}
\hline 8 & $\begin{array}{l}\text { we are pleased to learn...; } \\
\text { we cordially invite you to... }\end{array}$ & --- & --- \\
\hline 9 & I'm delighted to hear of your... & please accept my... & --- \\
\hline 10 & --- & please do not hesitate to... & --- \\
\hline 11 & --- & --- & --- \\
\hline 12 & $\begin{array}{l}\text { our heartiest congratulations... } \\
\text { and best wishes for your... }\end{array}$ & --- & I would like to... \\
\hline 13 & $\begin{array}{l}\text { My fellow directors and I } \\
\text { are delighted that... }\end{array}$ & --- & I would like to convey... \\
\hline 14 & --- & --- & we'd like very much to... \\
\hline 15 & ...how pleased we were to... & --- & --- \\
\hline 16 & ...how very grateful I am... & --- & --- \\
\hline 17 & I have been especially pleased.. & --- & --- \\
\hline 18 & we wish to thank you... & --- & --- \\
\hline 19 & ... enjoy working for you & please do let us know... & --- \\
\hline Total & 19 & 6 & 6 \\
\hline
\end{tabular}

As shown above, person deixis is the strategy that is most frequently used in convivial business letters: 15 letters of a total of 19 employ the strategy and some letters use it more than once. Mitigation strategy is occasionally used (6 in 19), the same as the frequency in competitive business letters. Yet conventionalized indirectness (6 in 19 ) is less used in convivial business letters than that in competitive business letters (13 in 19).

The speech acts of invitation, welcome, congratulations and thanks belong to the convivial category, and these types of speech acts often bring benefits to others. Pragmatic empathy inherently requires interlocutors to be polite, that is, people should maximize benefits to others while minimize costs to others. The use of first person is a way to achieve politeness because when making utterances led by first person, the writers can have their positive emotions expressed naturally. For example,

(9) It has been more than six months since we had the opportunity to service your automobile, and we've missed you (Cai, 2003).

(10) We have set aside the hours between 8:00 A.M. AND 1:00 P.M., Monday through Friday for your convenience (Cai, 2003).

(11) I am delighted to hear of your being elected to the board of directors of the Orlando Chamber of Commerce (Cai, 2003).

Extracts (9) and (10) are drawn from an invitation letter sent by an automobile shop to its customers to invite them to enjoy a free inspection. Extract (9) is an utterance implying to its customers that their cars need to be maintained. However, by using the expression "since we had the opportunity to service your automobile, the writer successfully levels up the customers' status to maximize benefits to others and as a result achieve the empathy. Similarly, by using the expression "we have set aside... for your convenience, the writer weakens the fact that customers only have access to the inspection service in a certain period of time. Instead it is as if the shop made efforts to cater for the customer's schedule, which implies the shop's consideration for its customers, and thus empathy is achieved. Extract (11) is drawn from a letter of congratulation, and by starting the utterance with first person, the writer easily expresses his positive emotions to others, and thus empathy is also achieved. 


\subsection{Pragmatic Empathy in Collaborative Business Letters}

As collaborative business letters are written to exchange information, what concerns the parties involved the most is how to exchange information effectively whereas interactive function is put to the second place. Collaborative business letters are characterized by concise and precise language that convey information directly. Table 3 shows the use of each pragmatic empathy strategy in collaborative business letters.

Table 3. Pragmatic empathy in collaborative business letters

\begin{tabular}{|c|c|c|c|}
\hline Letter No & Person Deixis & Mitigation & $\mathrm{CI}$ \\
\hline 1 & $\begin{array}{l}\text { should..., you would hold } \\
\text { yourself responsible for }\end{array}$ & --- & --- \\
\hline 2 & the packing for Dubai is to be.. & --- & $\begin{array}{l}\text { we would like you to } \\
\text { have the goods packed... }\end{array}$ \\
\hline 3 & $\begin{array}{l}\text { the door of the automobile } \\
\text { must be locked before shipment; } \\
\text { they should be wrapped up...; }\end{array}$ & --- & --- \\
\hline 4 & the tea... should be packed in... & please mark our.. & --- \\
\hline 5 & the goods should be packed... & please see to it... & --- \\
\hline 6 & ...should be on your account & --- & --- \\
\hline 7 & --- & please inform us... & $\begin{array}{l}\text { we should be very } \\
\text { grateful if you }\end{array}$ \\
\hline 8 & the machine must be packed... & --- & --- \\
\hline 9 & --- & --- & --- \\
\hline 10 & --- & --- & --- \\
\hline 11 & if... your $\mathrm{L} / \mathrm{C}$ must reach us before... & --- & --- \\
\hline 12 & we hope you will let us have your fax... & --- & --- \\
\hline 13 & --- & please also have the expiry date... & --- \\
\hline Total & 10 & 4 & 2 \\
\hline
\end{tabular}

As displayed above, person deixis is a dominating strategy used to manifest empathy, which occurs 10 times in a total of 13 letters. Mitigation strategies and conventionalized indirectness strategies are sometimes used. Specifically, third person is frequently used to stipulate packing terms. By making utterances of passive voice led by third person, the writer shifts the pragmatic stance to the object being described (e.g., the packing, the door) as if he or she were talking about an objective fact. In contrast, using second person plus an imperative modal verb such as "you should" shows an imperative tone, and thus incurs face-threat. Look at the following examples:

(12) As some parts of the machines are susceptible to shock, the machines must be packed in seaworthy cases capable of withstanding rough handling (Dong, 2010).

(13) If you wish to have our goods transshipped at Hong Kong, your L/C must reach us well before the shipment month so as to enable us to book space with the Line's agents (Dong, 2010).

Extract (12) is drawn from a shipment letter which stipulates the way the goods are packed. Passive voice led by third person avoids imposing direct imperative tone on the hearer, making the request less imposing. Similarly, extract (13) uses third person "your L/C must..." instead of "you should...", making the stipulation less imperative.

\subsection{Pragmatic Empathy in Conflictive Business Letters}

Conflictive business letters are written out of the concern that such negative effects as broken relations or disputes might be incurred. In reality, however, most companies exchange conflictive business letters with the 
hope that disagreements can be resolved and business relations retained for further cooperation. Therefore, conflictive business letters are still empathy-oriented in terms of their interpersonal function. Table 4 shows the use of each pragmatic empathy strategy in conflictive business letters.

Table 4. Pragmatic empathy in conflictive business letters

\begin{tabular}{|c|c|c|c|}
\hline Letter No & Person Deixis & Mitigation & $\mathrm{CI}$ \\
\hline 1 & --- & the certificate evidenced that...; & --- \\
\hline 2 & --- & we have no choice but to... & --- \\
\hline 3 & --- & please give our claims your... & --- \\
\hline 4 & we had received the wrong goods. & $\begin{array}{l}\text { we found that; } \\
\text { please advise us...; } \\
\text { please also let us know... }\end{array}$ & --- \\
\hline 5 & a mistake has been made & $\begin{array}{l}\text { we found that...; } \\
\text { we found that...; } \\
\text { please make... }\end{array}$ & --- \\
\hline 6 & $\begin{array}{l}\text { it contained...; } \\
\text { a mistake was made, } \\
\text { we cannot but ask you... }\end{array}$ & $\begin{array}{l}\text { we found...; } \\
\text { we can only presume... }\end{array}$ & We shall be glad if you... \\
\hline 7 & only 147 cases were received by us & we feel it regrettable that...; & $\begin{array}{l}\text { we shall be very pleased } \\
\text { if you... }\end{array}$ \\
\hline 8 & --- & we found that... & --- \\
\hline 9 & --- & $\begin{array}{l}\text { but (we) found that...; } \\
\text { we ask you, therefore, to... }\end{array}$ & --- \\
\hline 10 & $\begin{array}{l}\text { the reason... is that the packing } \\
\text { material was improper }\end{array}$ & $\begin{array}{l}\text { we must ask that you... } \\
\text { the goods were found to...; }\end{array}$ & --- \\
\hline 11 & 20 bags had not been packed.. & it was found that... & --- \\
\hline 12 & $\begin{array}{l}\text { there are no grounds for } \\
\text { such a claim to be lodged against us }\end{array}$ & --- & --- \\
\hline 13 & --- & I'm afraid to say that... & --- \\
\hline 14 & --- & we regret to inform you... & --- \\
\hline Total & 8 & 19 & 2 \\
\hline
\end{tabular}

As shown above, two principal strategies are employed in conflictive business letters to express empathy: deixis and mitigation. First, the shift of deixis is frequently employed in the expressions of complaints. To be specific, in a total of 9 letters which make complaints, all of them make complaints led by the first or the third person rather than the second person as a way of weakening blame and showing empathy for the letter-receiver. For example:

(14) On opening the cases we found that we had received the wrong goods. We received a LP-868 instead of the LP-888 Laser Printer that we ordered (Dong, 2010).

(15) After unpacking this case we found it contained completely different articles, and we can only presume that a mistake was made and the contents of this case were for another order (Dong, 2010).

(16) However, we feel it regrettable that only 147 cases were received by us (Dong, 2010).

Extract (14) is drawn from a complaint letter written by a buyer to inform the seller that wrong goods have been shipped to them. Instead of saying "You have shipped to us the wrong goods", the writer uses such expressions as "we have received" and "we received" to convey the similar meaning. Such shift of deixis serves as the 
pragmatic stance marker and makes salient the pragmatic stance of the writer. The use of "we (have) received" implies that the writer only intends to make the accident of wrong shipment known to the seller, and the avoidance of "you" helps to weaken the fact that it is the seller that has caused the mistake, whereby the buyer intends to tell the seller that they are to resolve the disputes rather than provoking conflicts.

Similarly, in extract (15), despite the fact that the buyer has received discrepant articles due to a wrong delivery by the seller, the buyer makes a complaint with a sentence led by the third person deixis "it", stating "it contained completely different articles" instead of asserting "you delivered wrong articles to us". The third person pronouns indicate larger social distance than the second person deixis and thus lower the closeness (Ran, 2007). By using "it" instead of "you", the writer makes it clear that they view this incident from the perspective of the articles and thus psychologically separates the article-seller from the incident, which helps to weaken the fact that it is the seller who has made the wrong delivery, and thus shows the buyer's consideration and sincerity. In a word, shifts of deixis show different pragmatic stances, and thus achieve empathy.

The same is true of extract (16). The seller writes a complaint letter to the buyer to inform that they have received the goods with a shortage. By saying "only 147 cases were received by us", the seller avoids referring to the buyer's will in the incident, showing their consideration for the latter and retaining their business relations.

Second, mitigation as a strategy is often found in the expressions of declining and claim. When investigating the speech acts of declining and claim, a total of 20 pieces of letters are manually inspected to identify such speech acts, 14 of which are complaint and claim letters (conflictive business letters) from Dong (2010) and 6 are claim and settlement letters from Cheng (2011). Claim is, in a general sense, a speech act of asking others to do something, and yet differs from such speech acts as request or invitation because people file claims to uphold their rights offended. In business letters, there are various ways of realizing the speech act of asking others to do something. In this regard, only those sentences expressing buyers' demand for target articles or compensation from the sellers are identified as claims in letters for analysis. Declining often occurs in conflictive business letters when sellers express their attitude towards buyers' claim, which may be a promise for repair or a decline to compensate. Therefore, sentences that show sellers' declining both explicitly or implicitly are counted.

In a total of 20 pieces of conflictive letters, 14 contain either claims or declines and 9 of them are expressed in mitigation. Analysis suggests that mitigation involved in all the 8 sentences are either illocutionary mitigation or perlocutionary mitigation.

Request markers such as "please" and "we ask you to" are frequently used in making claims. For example:

(17) Please advise us when we can expect to receive our order, as some of our customers have been waiting for up to one month (Dong, 2010).

(18) As we need the articles ordered to complete our range of cutlery, please make arrangements to dispatch the missing items at once (Dong, 2010).

(19) The Survey Report is forwarded evidencing damage to be the result of faulty packing. We ask you, therefore, to send us a cheque for US\$110.00 to cover the cost we paid for the survey Report.

(20) As the tea is no longer fit for people drinking, we must ask that you compensate us for the loss.

Empathy is both an effect of and the pragmatic psychological mechanism for mitigation (Li, 2012). Viewed from the perspective of empathy, the letter-writers could have make claims directly using short imperatives as they enjoy higher power in such affairs. But by using request markers such as "please" in extract (17) and "we ask you" in extract (18) and extract (19), the letter-writers show concerns and courtesy for the letter-receivers, making the former's attitude sincerer and the claims easier to be accepted by the letter-receivers.

Concern-showing devices are often employed in making declines as well as claims. For example:

(21) The materials are quite unsuitable to the needs of our customers and we have no choice but to require you to refund the invoice amount and inspection fee amounting to US $\$ 150,000$ (T. C. Cheng \& X. Cheng, 2011).

(22) But I'm afraid to say that all the cases were in perfect condition at the time they were loaded, as is evidenced by our clean Bill of Lading (Dong, 2010).

(23) We regret to inform you, therefore, that we cannot give you a refund because the goods are of salable quality (Dong, 2010).

Concern-showing, as a sub-strategy of perlocutionary mitigation, is used by the speaker to comfort the hearer when the former anticipates that his or her speech act may exert negative effects on the latter. In extract (21), the buyer files claims against the seller for refund due to the unsatisfactory goods. Here "we have no choice but to 
require" in extract (21) is used instead of "file claims". The letter-writer is aware that their request for refund might cause trouble for the letter-receiver, so he/she uses "we have no choice but" to show their concern for the latter and that they are forced to make such claim. Extracts (22) and (23) convey sellers' decline for compensation. Similarly, the sellers are quite clear that their decline will damage the buyers' face as well as their benefits. So from the empathy perspective, they use "I'm afraid to say" and "we regret to inform you" to show their concerns for the buyers and make their declines more acceptable.

\section{Conclusion}

This article discusses the explanatory power of pragmatic empathy as a grand strategy in business letter writing and its manifestation in writing skills. It is found that pragmatic empathy, which is manifested out of various empathetic concern in different types of business letters, can serve as a grand strategy in business letter writing. Specifically, in competitive business letters, whose empathetic concern is to persuade the reader to do something as requested while establishing and maintaining good business relationships, first person pronouns and conventionalized indirectness are often employed. In convivial business letters, whose empathetic concern is to express their sincere and positive attitude to the reader, first person is often used to express the empathetic consideration for the reader. In collaborative business letters, whose empathetic concern is to convey important information as fast and precise as possible, third person is frequently used to make the utterance as clear and polite as possible. In conflictive business letters, whose empathetic concern is to make declines to or claims against the receivers without breaking their business relations, first and the third person pronouns and mitigation strategies are frequently used.

In a word, collaborative business letters are exchanged for neutral-news messages and thus calls for the least empathetic concern, and convivial business letters are exchanged for good-news messages and empathy presents itself at the lexical level. Competitive and conflictive business letters convey persuasive messages and bad-news messages respectively and they call for more pragmatic strategies, i.e., deixis shift, conventionalized indirectness and mitigation. The shifts of deixis in both types of letters show that it is definitely a pragmatic stance marker.

There are also some limitations in this study, though. First, the corpus collected are not raw data due to the difficulty in data collecting. Future research may carry out relevant studies on the basis of raw data to generate more practical conclusions. Second, the sample is not large enough to obtain desired findings. Future research may conduct such studies on a data set as large as possible so that the findings will be more reliable and convincing.

\section{Acknowledgments}

The authors gratefully acknowledge the financial support by a research grant from Guandong University of Foreign Studies (17SS03).

\section{References}

Argaman, E. (2007). With or without 'it': The role of empathetic deixis in mediating educational change. Journal of Pragmatics, 39, 1591-1607. https://doi.org/10.1016/j.pragma.2007.02.005

Bachelor, A. (1988). How clients perceive empathy: a content analysis of 'received' empathy. Psychotherapy, 25, 227-240. https://doi.org/10.1037/h0085337

Brown, H. D. (2006). Principles of Language Learning and Teaching. Pearson Longman.

Brown, P., \& Levinson, S. (1987). Politeness: Some universals in language usage. Cambridge: Cambridge University Press. https://doi.org/10.1017/CBO9780511813085

Cai, Y. (2003). Practical Business Letters. Beijing: Press of Beijing University of aeronautics and astronautics.

Cao, L. (2002). English Business Letters. Beijing: Foreign Language Teaching and Research Press.

Cheng, T. C., \& Cheng, X. (2011). International Business Correspondence in English. Nanjing: Southeast University Press.

Davis, M. H. (1996). Empathy: A Social Psychological Approach. Boulder: Westview Press.

Dong, J. L., Hao, J. Y., \& Zheng, L. X. (2013). Communicating in International Business. Beijing: China Machine Press.

Dong, X. B. (2010). English Correspondence for International Trade. Beijing: Tsinghua University Press \& Beijing Jiaotong University Press.

Feng, H. Y., \& Du-Babcock, B. (2016). "Business is Business": Constructing cultural identities in a persuasive 
writing task. English for Specific Purposes, 44, 30-42. https://doi.org/10.1016/j.esp.2016.06.004

Gast, V., Deringer, L., Haas, F., \& Rudolf, O. (2015). Impersonal uses of the second person singular: A pragmatic analysis of generalization and empathy effects. Journal of Pragmatics, 88, 148-162. https://doi.org/10.1016/j.pragma.2014.12.009

He, Z. R. (1991). Pragmatic Empathy in Verbal communication. Foreign Language Teaching and Research, 4, 11-15.

He, Z. R., \& Ran, Y. P. (2006). An Introduction to Pragmatics. Changsha: Hunan Education Press.

Hoffman, M. (2000). Empathy and Moral Development: Implications for Caring and Justice. New York: Cambridge University Press. https://doi.org/10.1017/CBO9780511805851

Huang, Y. (2002). Reconstructing the Categorization of English Business Letters with Reference to the Categorizing Model of Speech Acts. Journal of Nanjing University of Aeronautics \& Astronautics (Social Sciences), 4(4), 62-65.

Leech, G. N. (1983). Principles of Pragmatics. London: Longman.

Levinson, S. C. (2001). Pragmatics. Beijing: Foreign Language Teaching and Research Press.

Li, A. Q. (2015). Pragmatic empathy and English language teaching. (Unpublished thesis). University of Southwest University, Chongqing, China.

Li, H. H. (2008). A pragmatic study of mitigation in television interview talks. Unpublished PhD dissertation of Guangdong University of Foreign studies.

Li, Hai-hui. (2012). A Pragmatic-empathic View of Mitigation. Jinan Journal (Philosophy and Social Sciences) (9), 117-123.

Li, W. M., Liu, S. F., \& Guo, L. (2001). On Combination of Relevance Principle and Politeness Principle in Business Context. Journal of China University of Mining \& Technology (Social Sciences), 3, 144-150.

Liu, J. S., \& Zhou, Y. (2008). The Mechanism and Affecting Factors of Children's Empathy. Psychological Science, 4, 917-921.

Liu, Y. H., \& Zheng, S. (2015). The Application of Politeness Strategies to Business English Correspondence Writing. Journal of SUIBE, 22(1), 79-88.

Liu, Y. H., \& Wang, Y. (2016). New Economy Principle and the Optimal Distribution of Business English Correspondence. Journal of SUIBE, 23(5), 73-83.

Ma, X. M., \& He, C. C. (2011). On Pragmatic Empathy in Business English Communication. Journal of Xuzhou Normal University (Philosophy and Social Sciences Edition), 37(6), 146-149.

Mao, Y. S., \& Pei, T. Y. (2013). A micro-test of "Women's Discourse Hypothesis": a case study of Chinese mitigators. Journal of Nanjing University of Posts and Telecommunications (Social Science), 1, 81-87.

Ran, Y. Y. (2007). Deixis Selection: Pragmatic Stance, Pragmatic Empathy and De-empathy. Foreign Language Teaching and Research, 39(5), 331-337.

Reiter, R. M., Rainey, I., \& Fulcher, G. (2005). A Comparative Study of Certainty and Conventional Indirectness: Evidence from British English and Peninsular Spanish. Applied Linguistics 26 (1), 1-31. https://doi.org/10.1093/applin/amh018

Si, F. C. (2003). On the Politeness Principle for Writing Business Letters in English. Journal of Huaqiao University (Philosophy and Social Sciences), 4, 103-106.

Sorrels, B. D. (1984). Business Communication Fundamentals. Ohio: Charles E. Merrill Publishing Company.

Verschueren, J. (1999). Understanding Pragmatics. Beijing: Foreign Language Teaching and Research Press. https://doi.org/10.1016/S0378-2166(98)00097-6

Wang, H. J. (1995). The complete applying documents of foreign trade. Beijing: Modern Press.

Wilkinson, W. C., Wilkinson, D. C., \& Vik, G. N. (1986). Communicating through writing and speaking in business. Illinois: IRWIN.

Zhang, J., \& Miao, X. W. (2004). Pragmatic Empathy from the Perspective of Interpersonal Function. Foreign Language Education, 25(5), 41-44.

Zhou, R. Q. (2007). The Application of Pragmatic Principles in English Business Letter Writing. Journal of 
Guangdong University of Foreign Studies, 18(1), 92-94, 101.

\section{Copyrights}

Copyright for this article is retained by the author(s), with first publication rights granted to the journal.

This is an open-access article distributed under the terms and conditions of the Creative Commons Attribution license (http://creativecommons.org/licenses/by/4.0/). 